\title{
Lake Trout Spawning in Lake Tahoe: Egg Incubation in Deepwater Macrophyte Beds
}

\author{
DAVID A. BEAUCHAMP \\ Department of Fisheries and Wildlife, Utah State University \\ Logan, Utah 84322, USA \\ Brant C. Allen and Robert C. Richards \\ University of California-Davis, Tahoe Research Group \\ Post Office Box 633, Tahoe City, California, 95730, USA \\ WAyNe A. Wurtsbaugh \\ Department of Fisheries and Wildlife, and Ecology Center \\ Utah State University \\ Charles R. Goldman \\ Division of Environmental Studies, University of California \\ Davis, California 95616, USA
}

\begin{abstract}
Although most populations of lake trout Salvelinus namaycush spawn over rocky shoals, use of these substrates by lake trout has not yet been found in Lake Tahoe. Large cobble substrate exists at depths less than $20 \mathrm{~m}$, and steep, fractured, rocky substrate can be found in isolated areas from the surface down to at least $100 \mathrm{~m}$, but no evidence of spawning activity in these areas has been found. Instead, at least a portion of the population spawns on deepwater mounds (40-60 m deep) over beds of the macrophyte Chara delicatula. This is the first known report of lake trout spawning over macrophyte beds. We hypothesize that this population originated from a deep-spawning stock and that the macrophyte beds on these mounds may provide some of the best deepwater incubation habitat in the lake. Although egg predation by intermediate sizes of lake trout (375-500 $\mathrm{mm}$ fork length) was substantial, the mounds appeared to be a refuge from the potentially more effective invertebrate and small vertebrate egg predators. The oxygen and temperature regime within the macrophytes was suitable for egg development, and the eggs that infiltrated deeply among the plant strands were anchored against currents and were presumably protected from further predation by lake trout.
\end{abstract}

Although lake trout Salvelinus namaycush in Lake Tahoe have supported a popular year-round trophy sport fishery for over 80 years, little is known about where they spawn. Investigators working on other lakes have reported that good spawning substrates used by lake trout consist of cobble, boulder, or broken angular rock wherein interstitial spaces provide protection and support for the eggs (e.g., Martin and Olver 1980; Dorr et al. 1981; Nester and Poe 1987; Edsall et al. 1989). In Lake Tahoe, spawners congregate in several discrete, deepwater areas from September through November, where anglers consistently catch both mature and immature fish by jigging. However, from the fishery data alone we were unable to determine whether the lake trout were spawning in these areas, or were merely staging there during the day and spawning over suitable substrate elsewhere after dark. Here, we verify that a portion of the lake trout population in Lake Tahoe spawned over deepwater beds of the macrophyte Chara delicatula, and we examine some of the physical, chemical, and biological features of these areas that allow successful spawning to occur.

\section{Study Area}

Lake Tahoe is a deep, moderately large lake (mean depth, $313 \mathrm{~m}$; maximum depth, $505 \mathrm{~m}$; area, $500 \mathrm{~km}^{2}$ ) at an elevation of $1,905 \mathrm{~m}$ in the Sierra Nevada of California and Nevada. It is ultraoligotrophic with Secchi depths ranging from 16 to 30 m (Goldman 1988; Loeb and Hackley 1988). Photosynthesis by benthic algae and plants occurs to depths of $198 \mathrm{~m}$ (Frantz and Cordone 1967; Loeb 1980). Chara sp. composed approximately $80 \%$ of the macrophyte biomass between 6 and $100 \mathrm{~m}$, and its distribution was reportedly widespread around the lake in the 1960s (Frantz and Cordone 1967).

The self-sustaining lake trout population was 
introduced into Lake Tahoe in 1889 (Miller and Alcorn 1945), and now makes up the majority of the sport catch (Cordone and Frantz 1966; T. Frantz, Nevada Department of Wildlife, and R. Wickwire, California Department of Fish and Game, unpublished data). From September through November, lake trout congregate around the top, edge, and slope of subsurface mounds (called the South Shore Mounds) in the southeast region of the lake (Figure 1). The tops of the mounds are 45-55 $\mathrm{m}$ deep, and each is approximately 2,000 $\mathrm{m}^{2}$ in area. The mounds are surrounded by water at least $105 \mathrm{~m}$ deep; the shallowest approach is from the southeast shore.

Our underwater video survey of the mounds showed that the macrophyte beds provided the only cover for incubating eggs on the mounds. We visually estimated that $50-70 \%$ of the tops of the mounds were covered with dense beds of Chara delicatula $15-30 \mathrm{~cm}$ tall. The remainder of the top and the slopes of the mounds were composed of organic silts and solid sedimentary rock or clay.

\section{Methods}

We combined information from sport-caught lake trout, echograms, underwater videos, and bottom sampling to verify that spawning occurred over deepwater macrophytes. We collected stomachs of lake trout from fishing guides and by port sampling during the spawning season. The samples were segregated by fish size, and depth, location, and method of capture (jig- versus trollcaught fish). Lake trout caught with jigs were taken from the aggregations of fish closely associated with the South Shore Mounds. Troll-caught fish were captured elsewhere in the lake away from the mounds. We recorded the sex, maturity, and spawning condition of the lake trout. The stomach contents were separated into categories (species of fish, lake trout eggs, mysids Mysis relicta, signal crayfish Pacifastacus leniusculus, and other minor prey). The prey items were recorded as the percentage of the total wet weight of the stomach contents for individual fish.

We surveyed the mounds and other suspected spawning areas with commercial-grade echosounders $\left(50 \mathrm{kHz}, 11^{\circ}\right.$ half-beam angle) to locate aggregations of lake trout and to characterize their diel distribution pattern. We searched for daytime aggregations by running sinusoidal transects between the 10- and 80-m depth contours in October 1990. When aggregations were located, either by echosounding or by the jig fishery, we ran short ( 5 $\mathrm{min})$, repetitive echosounding transects perpen-

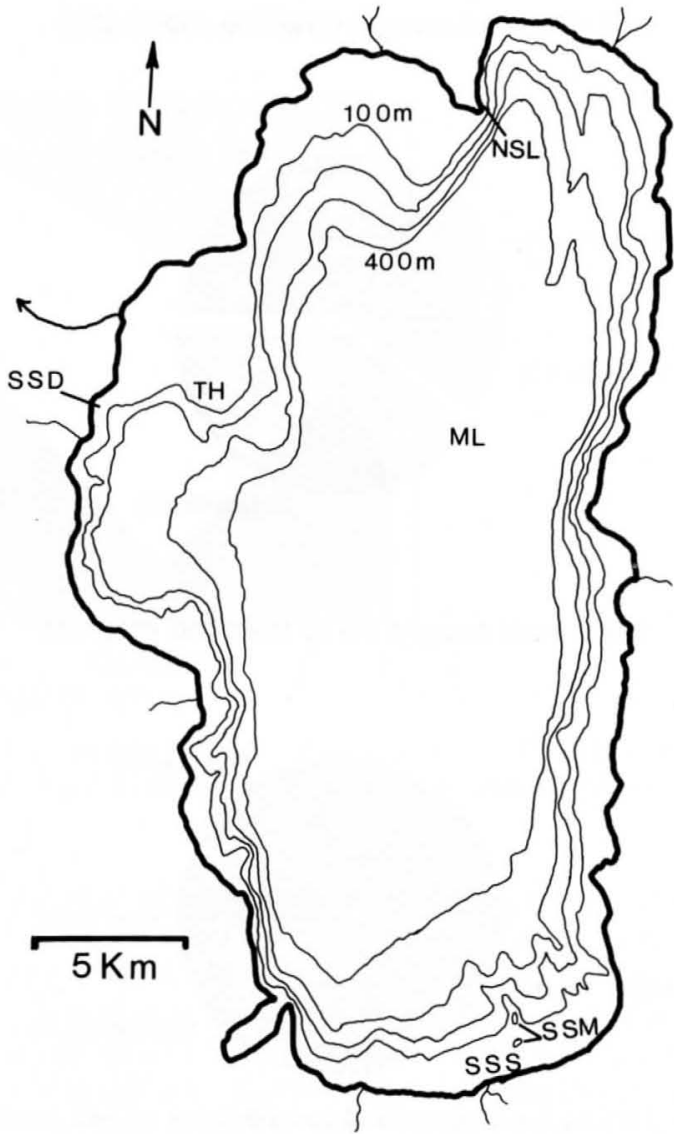

FIGURE 1.-Bathymetric map of Lake Tahoe with the location of the South Shore Mounds (SSM), South Shore Slope (SSS), Tavern Hole (TH), Sunnyside (SSD), North Stateline (NSL), and the midlake limnological sampling station (ML).

dicular to the slope of the lake bottom for $2-4 \mathrm{~h}$ during the day, night, and crepuscular periods in October, November, and December. The chart recordings provided qualitative information on the relative density and diel depth distribution of lake trout in these aggregations.

Underwater video surveys with a remotely operated vehicle (ROV: Deep Sea Systems Mk-I Mini Rover) were used to identify the targets on the echogram, resolve the near-bottom distribution of fish that were undetectable by the echosounder, and examine the substrate. Surveys with the ROV were done in conjunction with the echosounding surveys. The ROV provided its own lights and could operate to a depth of $152 \mathrm{~m}$.

We used the ROV and bottom samples to locate areas of egg deposition. Exposed substrates were surveyed for eggs with the ROV. Two lines of five egg traps were set on the South Shore Mounds in 


\section{Lake trout caught over the mounds}

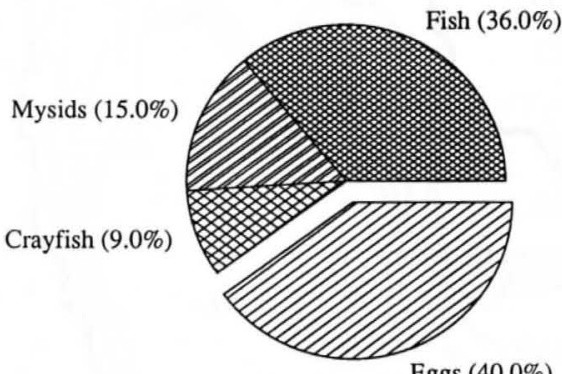

Eggs $(40.0 \%)$

\section{Lake trout caught away from the mounds}

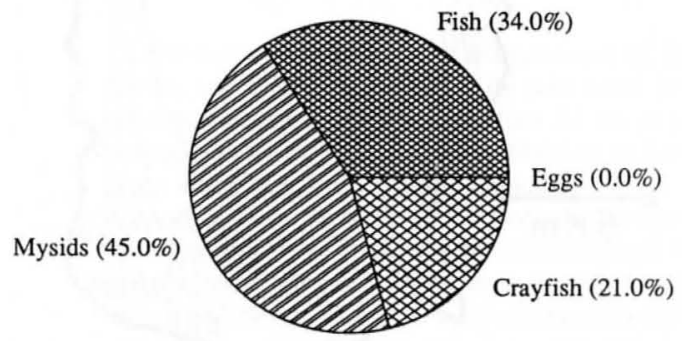

FIGURE 2.-Proportional contributions of lake trout eggs and other prey to the diets of lake trout jigged ( $N$ $=63$ ) on the South Shore Mounds and of lake trout trolled $(N=65)$ in other areas of Lake Tahoe during and shortly after the spawning season (November to January).

early October, but could not be retrieved because the buoy line was lost within the first month. We scraped a small mat (approximately $2.4 \mathrm{~m}^{2}$ in area and $45 \mathrm{~L}$ in uncompressed volume) of mud and the attached macrophytes from the mound with a 1.2-m-wide mysid sled (Richards et al. 1975). In order to minimize damage to a valuable and potentially rare habitat, we collected the minimum amount of plant material necessary to demonstrate the presence or absence of lake trout eggs.

We used baited minnow traps to estimate the relative abundance of invertebrate and small vertebrate egg predators on the mounds and at similar depths at three other sites: (1) along the ascending shoreward slope (silty substrate) directly south of the mounds; (2) at Tavern Hole, on a clay-silt shelf and slope with occasional, sparse, single-layer patches of cobble; and (3) on a steep, fractured, rock slope near North Stateline Point (Figure 1). These sites were selected to compare the potential predation pressure on the mounds with that in other areas and on other types of substrate at similar depths in the lake. Of these sites, only Tavern Hole showed similar aggregations of lake trout during the spawning season. Three traps were set for two nights at each site at least twice during the spawning season. Two replicate sets of minnow traps were set monthly at depths of $3,10,20,30$, 40 , and $50 \mathrm{~m}$ at North Stateline and at Sunnyside, a site having only silt substrate at all depths greater than $5 \mathrm{~m}$ (Figure 1).

Dissolved oxygen and temperature profiles were measured monthly at the South Shore Mounds and biweekly at a midlake station; we used a YSI probe (air calibration) and a Martek thermistor for these purposes. Temperatures were measured at the surface, at $2 \mathrm{~m}$, at $5-\mathrm{m}$ intervals from 5 to 15 $\mathrm{m}$ below the top of the hypolimnion (about 105 $\mathrm{m}$ ), and at 50-m intervals thereafter. Dissolved oxygen concentrations were measured at $10-\mathrm{m}$ depth intervals to $60 \mathrm{~m}$. With the ROV, we visually positioned the probe to measure directly above and within the macrophytes and on the exposed silt substrate.

\section{Results}

Examinations of both mature and immature lake trout caught in the vicinity of the mound suggested that spawning occurred on the mounds. Although lake trout were found in the vicinity of the mounds all year, densities were considerably higher, and more larger adults were present, from September through November (J. Vogel, sport fishing charter boat guide, Zephyr Cove, Nevada, personal communication). In September, most of the adult lake trout caught over the mounds were mature but not ripe, whereas by the end of November, most adults were spawned out. Lake trout eggs made up an average of $40 \%$ of the diet (by weight) of jig-caught lake trout from the mounds during November and December in 1989 and 1990 (Figure 2); the eggs amounted to $58 \%$ of the diet in November, $22 \%$ in December, and 0\% in January. Strands of Chara delicatula and traces of mud were commonly found in the stomachs containing eggs, but were absent from empty stomachs and those containing other prey. During the same period, only trace amounts of eggs were found in the stomachs of lake trout caught by trolling in other areas (Figure 2). The magnitude of egg predation varied among the sizeclasses of lake trout caught on the mounds $(P<$ 0.05 , one-way analysis of variance) and was high- 


\section{$\square_{\text {EGGS }} \square_{\text {CRAYFISH }}$}

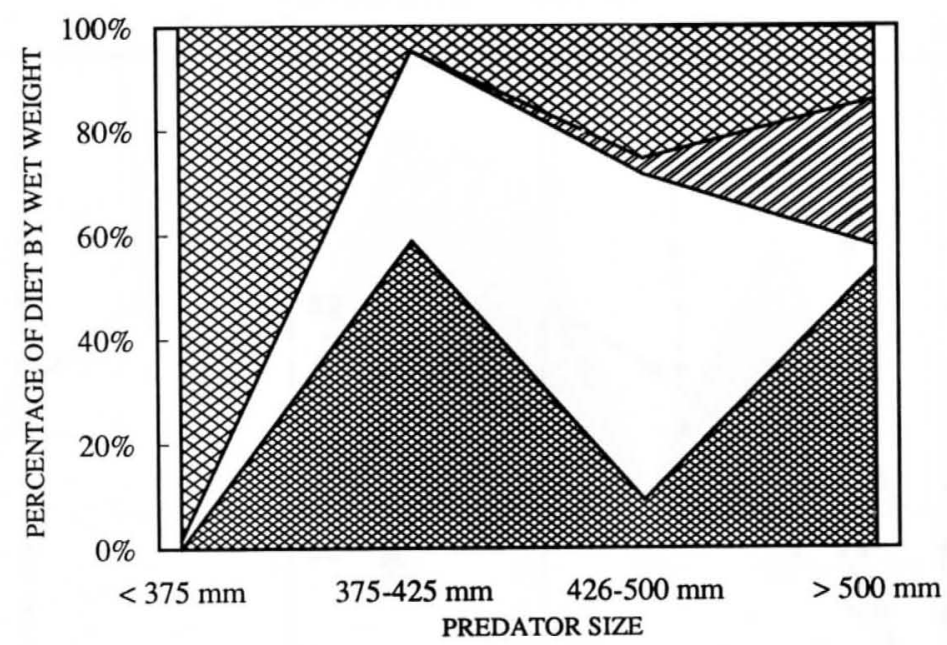

FIGURE 3. - Diet compositions of different size-classes of lake trout ( $<375 \mathrm{~mm}$ fork length, $N=8 ; 375-425 \mathrm{~mm}$, $N=15 ; 426-500 \mathrm{~mm}, N=14 ;>500 \mathrm{~mm}, N=26)$ jigged on the South Shore Mounds during and shortly after the spawning season (November to January).

est for the intermediate sizes (375-500 mm fork length; Student-Newman-Keuls multiple-range test) (Figure 3). Of the fish that consumed eggs, $56 \%$ were immature, $25 \%$ were ripe but had not spawned, $12 \%$ were spent males, and $6 \%$ were spent females. The spent females contained less than 0.1 $\mathrm{g}$ of eggs in their stomachs, whereas the mean mass of eggs in the other stomachs was $2.6 \mathrm{~g}$ (SE, 0.9 g).

Dense aggregations of lake trout formed around the mounds (40-65 $\mathrm{m}$ deep) between sunrise and 0900 hours, and they persisted through the daylight and early twilight hours. Both angler catches and underwater video confirmed that targets on the echograms were lake trout suspended 2-5 m above the substrate. No other fishes were observed by underwater video, nor were any caught in baited minnow traps or fyke nets set on the mounds. During the late twilight period, the fish dispersed over a wider vertical range above the mounds. Few fish were detected on the echosounder at night, but all of the lake trout observed by underwater video were within $10 \mathrm{~cm}$ of the bottom (and thus not detectable with an echosounder), indicating that the fish settled onto the substrate at night rather than leaving the area. Lake trout appeared to behave normally around the lighted ROV unless they were pursued or directly illuminated by the headlights for prolonged periods (>5-10 s).

No eggs were seen during September-November ROV surveys of the bare sediment, bedrock, and clay substrates; because we could not adequately examine the dense macrophyte beds this way, we dredged up a $2.4-\mathrm{m}^{2}$ mat of Chara and attached mud for examination. The sample contained 16 lake trout eggs, most of which were tangled in the lower third of the Chara strands within $8 \mathrm{~cm}$ of the mud. The mean egg diameter was 5.7 $\pm 0.2 \mathrm{~mm}(2 \mathrm{SE})$ compared to a mean diameter of $5.8 \mathrm{~mm}$ for lake trout eggs measured in November by Hanson and Wickwire (1967). Six of the eggs (38\%) were viable, and two had reached the eyed stage.

Temperature and dissolved oxygen concentrations on the mounds were favorable for the incubation of lake trout eggs (Garside 1959). Temperatures at depths of $40-55 \mathrm{~m}$ ranged from 5 to $9^{\circ} \mathrm{C}$ during the incubation period (Figure 4). Dissolved oxygen concentrations at midday ranged from 7.2 to $8.8 \mathrm{mg} / \mathrm{L}$ in the macrophyte bed. The diel minimum oxygen concentrations on the mounds (predawn oxygen levels in the macrophyte beds below the thermocline) ranged from 5.6 to $6.4 \mathrm{mg} / \mathrm{L}$ (mean, $6.1 \mathrm{mg} / \mathrm{L}$ ), and were well above the tolerance limits for lake trout eggs (Garside 1959).

Egg predators other than lake trout were not found in the vicinity of this spawning area. Underwater video surveys revealed no signal crayfish or other fishes associated with the macrophytes or the exposed substrate. One Piute sculpin Cottus beldingii $(84 \mathrm{~mm})$ was captured in the mat of mac- 


\section{Temperature}

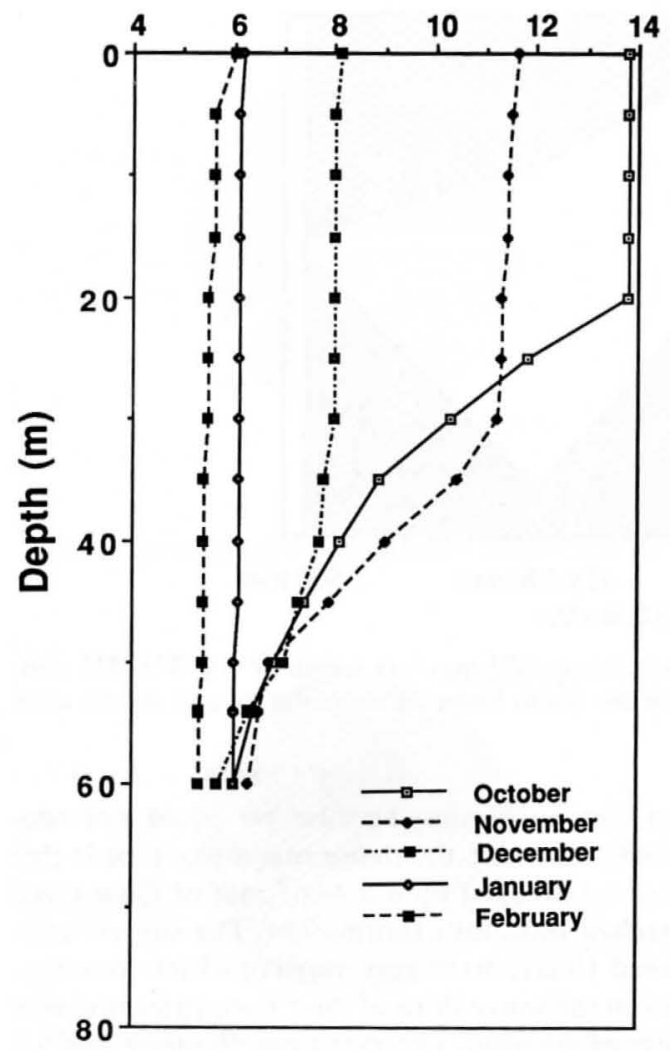

Dissolved oxygen $\mathrm{mg} / \mathrm{L}$

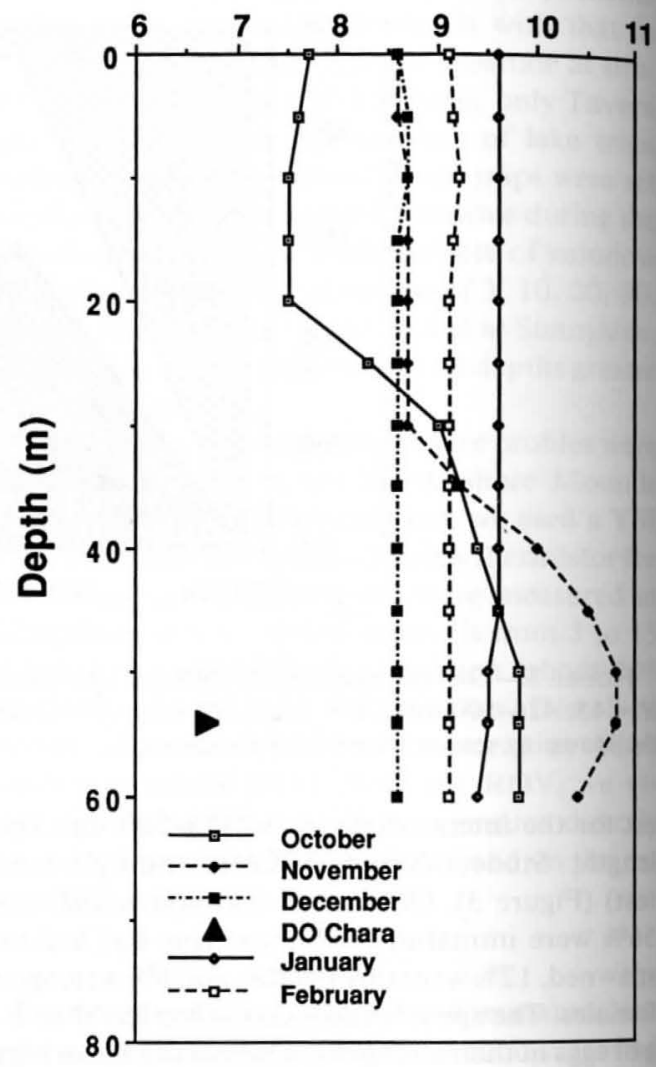

FIGURE 4.-Temperature and dissolved oxygen (DO) profiles in Lake Tahoe during the spawning and incubation season for lake trout eggs. The diel minimum DO level (filled triangle) was measured $(N=7)$ just before sunrise on December 6, 1990, by placing a probe just above the mud inside a dense patch of the macrophytes on the South Shore Mounds.

rophytes we examined for eggs, but only amphipods were found in its stomach. No potential predators were captured in seven minnow trap sets on the mounds, nor in sets at similar depths $(40-80$ m) at North Stateline, the South Shore Slope, and Sunnyside; however, 168 signal crayfish were captured in nine baited minnow trap sets over the same depth range at Tavern Hole, an area of silt and scattered cobble with similar aggregations of lake trout. From November through March, the density of small fishes was greatest at depths of $10-20 \mathrm{~m}$, and minnow-trap catches of fishes dropped to zero below $30 \mathrm{~m}$ (Figure 5).

\section{Discussion}

This is the first report of lake trout spawning on deepwater beds of macrophytes (C. Krueger, Cornell University, personal communication). This discovery is significant, because the cobble, boul- der, and broken rock substrates typically used by other lake trout populations have not been found at the depths and locations where spawning aggregations have been identified in Lake Tahoe thus far. Tavern Hole, another area where lake trout aggregate in autumn, has a clay and silt bottom with cobble that is too scattered to provide interstices for protecting incubating eggs. Some complex rocky habitats exist at shallower depths ( $0-$ $20 \mathrm{~m}$ ), but no evidence of spawning has been found in egg traps or on echograms from these areas, even when these sites were directly upslope from deepwater aggregations of lake trout. Hacker (1957) reported similar behavior by lake trout of Lake Michigan origin in Green Lake, Wisconsin. Historical stocking records are unclear as to the original source of the Lake Tahoe population, but the depth distribution (40-60 m), coloration (red fins during the spawning season), and morphology 


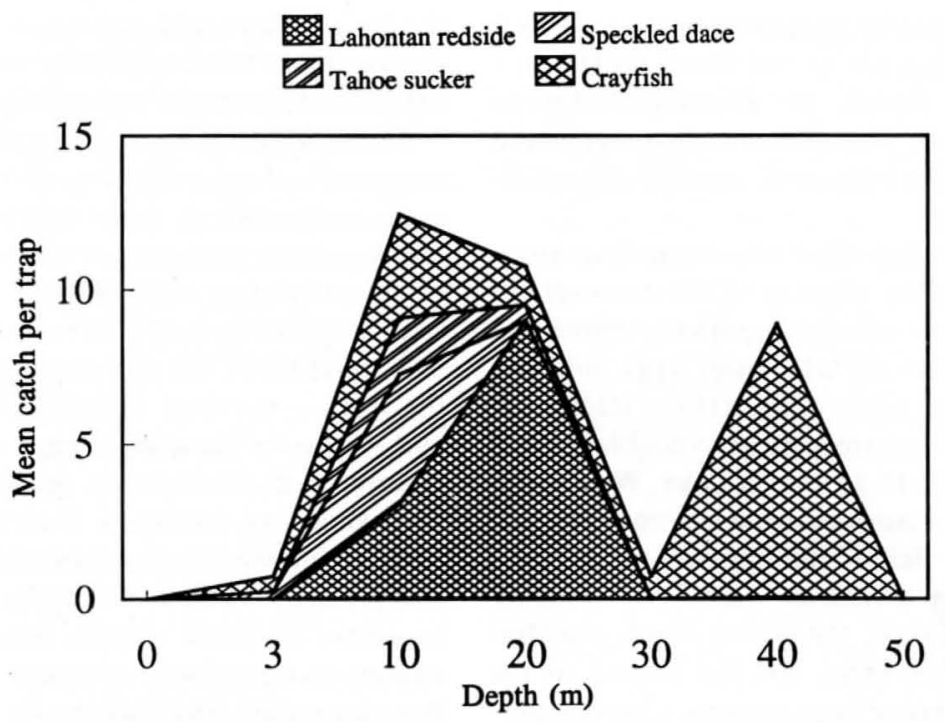

Figure 5.-Winter depth distributions $(0-50 \mathrm{~m})$ of small fishes and crayfish that could feed on lake trout eggs. Samples were collected with baited minnow traps. All sampled areas were pooled.

(large, slender bodies) of spawning and staging fish are similar to those of lake trout that historically spawned on Julian Reef (50 m deep) in Lake Michigan (Brown et al. 1981).

Although spawning on macrophytes is unusual for lake trout and salmonids in general, this habitat provides the basic requirements for successful egg incubation. The strands of Chara should anchor and support the eggs sufficiently in the currents of 10-20 cm/s (Dillon and Powell 1976, 1979; Strub and Powell 1986) that occur in the mixed layer of Lake Tahoe before and during destratification in late autumn. Eggs deposited over exposed substrate at these depths could either be swept into less favorable habitats for incubation or juvenile rearing, or be eaten by lake trout, crayfish, or smaller fishes. Whether lake trout select these macrophytes for spawning substrate or are merely spawning where macrophytes occur incidentally has not been determined directly; however, the absence of eggs over the bare substrate on the mounds suggest that either lake trout do not deposit eggs there, or that the eggs are eaten or swept away by the currents. During a 1979 limnological investigation of the mounds from the Pioneer I submersible, lake trout were observed cleaning substrate in the Chara beds rather than over the other substrate (C. R. Goldman, unpublished data).

Lake trout were the primary egg predators on the South Shore Mounds. Most of this predation was attributed to the intermediate sizes of fish present, and these sizes corresponded with the range over which the percentage of mature adults shifts from 3 to $61 \%$ for males and from 0 to $47 \%$ for females (Hanson and Wickwire 1967). Immature lake trout are generally uncommon on the spawning grounds in most lakes (Martin and Olver 1980), but the only fish to consume substantial amounts of eggs in Lake Tahoe were either immature lake trout, prespawning adults, or spawned-out males. This pattern suggests some interesting differences between spawned-out males and females regarding the trade-offs between acquiring energy and the risk of eating one's own offspring.

We suspect that the eggs that settle in more exposed positions along the top and periphery of the macrophytes were readily eaten, whereas the eggs that settled deeper among the strands of Chara delicatula experienced higher survival rates. This supposition is supported by several observations. First, all of the eggs we recovered were tangled among the lower (inner) portions of the macrophyte strands; this indicates that the eggs do indeed penetrate deep into the macrophyte beds. Second, extensive video surveys with the ROV failed to detect any eggs on the exposed substrate or along the top or outer margins of the macrophyte beds. Third, only small fragments of macrophytes were found in the stomachs containing eggs; separating eggs from the dense inner regions of the macrophytes would be difficult, and we would expect considerably more plant material in the stomachs if the more protected eggs were consumed. Instead, the small amounts of plant frag- 
ments in stomachs with eggs seem consistent with fish eating eggs exposed at the distal portions of the macrophytes. Finally, the dramatic decline in egg predation from November to January could reflect the seasonal attrition of exposed eggs available to lake trout.

Egg predators other than immature lake trout were very rare in the vicinity of the macrophyte beds. In other lakes, crayfish reportedly consumed significant numbers of lake trout eggs, and ate higher proportions when deep, narrow interstitial spaces in rocky substrate were unavailable (Horns and Magnuson 1981). In Green Lake, Wisconsin, stocked lake trout spawned over deep, exposed, soft substrate, but all of the eggs were consumed by mud puppies Necturus maculosus (Hacker 1957). In Lake Tahoe, the winter depth distribution of the smaller fishes did not extend to the depth of the spawning aggregations. Crayfish predation could significantly limit reproductive success in shallower exposed areas in Lake Tahoe. Abrahamsson and Goldman (1970) estimated that crayfish densities averaged $0.925 / \mathrm{m}^{2}$ between the shore and $40 \mathrm{~m}$ deep. We encountered crayfish down to $40 \mathrm{~m}$ during autumn and winter in areas with sparse rocky substrate during the egg incubation period, but none were found in the Chara beds or silty areas at the mounds, South Shore Slope, and Sunnyside. Abrahamsson and Goldman (1970) reported crayfish down to $200 \mathrm{~m}$ in Lake Tahoe, but $90 \%$ of the population remained above $40 \mathrm{~m}$.

The location and characterization of the spawning aggregation of lake trout at the South Shore Mounds will help focus future management and research objectives regarding lake trout population biology and recruitment. The spawning population on the South Shore Mounds certainly represents just a fraction of the total annual reproduction in the lake. The present population abundance, as suggested by the existing fishery, could not have been sustained solely by reproduction in this area. We expect that location of other spawning areas should be easier now that we have an idea of the behavior and habitat used by spawning aggregations. Only after an assessment of all spawning locations in the lake is completed will we be able to determine what proportion of lake trout spawning occurs over deepwater macrophytes. Knowing that lake trout can spawn over macrophytes may help scientists locate or establish spawning populations in other lakes. The extraordinary transparency of Lake Tahoe allows nonvascular plant growth to nearly $200 \mathrm{~m}$, a rare phenomenon among the lakes of the world, but more shallow-spawning stocks of lake trout might use macrophytes under certain conditions in less transparent lakes.

Future information on the nature and potential magnitude of egg predation within different depth strata and substrate types will be useful in determining which processes might be most important in constraining recruitment and influencing spawning strategies of lake trout. In the next phase of our research, we will experimentally evaluate the relative survival value of different substrates and depths for incubating eggs, and we will try to determine if the mounds provide island refuges from small egg predators. If certain stocks of lake trout are genetically predisposed to spawn within specific depth ranges, and if physical or biological processes at those depths impose further constraints on reproductive success, then these factors have important implications for stock selection in efforts to introduce, enhance, or reestablish lake trout populations in new or altered environments. Managers' expectations for lake trout recruitment should incorporate information on water quality, lake morphometry, substrate composition, and distribution of predators in a lake.

\section{Acknowledgments}

Funding was provided by the California Department of Fish and Game and the Nevada Department of Wildlife, and it was administered by the Tahoe Regional Planning Agency. We extend special thanks to Almo Cordone, Russ Wickwire, Ted Frantz, and fishing guides Mickey Daniels, Jeff Vogel, and Rick Mueller for their insights on the sport fishery.

\section{References}

Abrahamsson, S. A. A., and C. R. Goldman. 1970. Distribution, density and production of the crayfish Pacifastacus leniusculus Dana in Lake Tahoe, California-Nevada. Oikos 21:83-91.

Brown, E. H., Jr., G. W. Eck, N. R. Foster, R. M. Horrall, and C. E. Coberly. 1981. Historical evidence for discrete stocks of lake trout (Salvelinus namaycush) in Lake Michigan. Canadian Journal of Fisheries and Aquatic Sciences 38:1747-1758.

Cordone, A. J., and T. Frantz. 1966. The Lake Tahoe sport fishery. California Fish and Game 52:240274.

Dillon, T. M., and T. M. Powell. 1976. Low-frequency turbulence spectra in the mixed layer of Lake Tahoe, California-Nevada. Journal of Geophysical Research 81:6421-6427.

Dillon, T. M., and T. M. Powell. 1979. Observations of a surface mixed layer. Deep-Sea Research, Part A 26:915-932. 
Dorr, J. A., III, D. V. O'Connor, N. R. Foster, and D. J. Jude. 1981. Substrate conditions and abundance of lake trout eggs in a traditional spawning area in southeastern Lake Michigan. North American Journal of Fisheries Management 1:165-172.

Edsall, T. A., T. P. Poe, R. T. Nester, and C. L. Brown. 1989. Side-scan sonar mapping of lake trout spawning habitat in northern Lake Michigan. North American Journal of Fisheries Management 9:269-279.

Frantz, T. C., and A. J. Cordone. 1967. Observations on deepwater plants in Lake Tahoe, California and Nevada. Ecology 48:711-714.

Garside, E. T. 1959. Some effects of oxygen in relation to temperature on the development of lake trout embryos. Canadian Journal of Zoology 37:689-698.

Goldman, C. R. 1988. Primary productivity, nutrients, and transparency during the early onset of eutrophication in ultra-oligotrophic Lake Tahoe, California-Nevada. Limnology and Oceanography 33: 1321-1333.

Hacker, V. A. 1957. Biology and management of lake trout in Green Lake, Wisconsin. Transactions of the American Fisheries Society 86:71-83.

Hanson, J. A., and R. H. Wickwire. 1967. Fecundity and age at maturity of lake trout, Salvelinus namaycush (Walbaum), in Lake Tahoe. California Fish and Game 53:151-164.

Horns, W. H., and J. J. Magnuson. 1981. Crayfish predation on lake trout eggs in Trout Lake, Wisconsin. Rapport et Procès-Verbaux des Réunions, Conseil International pour l'Exploration de la Mer 178:299-303.
Loeb, S. L. 1980. Production of the epilithic periphyton community in Lake Tahoe, California-Nevada. Doctoral dissertation. University of California, Davis.

Loeb, S. L., and S. H. Hackley. 1988. The distribution of submerged macrophytes in Lake Tahoe, California and Nevada, and the possible influence of groundwater seepage. Internationale Vereinigung für theoretische und angewandte Limnologie Verhandlungen 23:1927-1933.

Martin, N. V., and C. H. Olver. 1980. The lake charr. Pages 205-277 in E. K. Balon, editor. Charrs, salmonid fishes of the genus Salvelinus. Dr. W. Junk, The Hague, Netherlands.

Miller, R. R., and J. R. Alcorn. 1945. The introduced fishes of Nevada, with a history of their introduction. Transactions of the American Fisheries Society 73:173-193.

Nester, R. T., and T. P. Poe. 1987. Visual observations of historical lake trout spawning grounds in western Lake Huron. North American Journal of Fisheries Management 7:418-424.

Richards, R. C., C. R. Goldman, T. C. Frantz, and R. Wickwire. 1975. Where have all the Daphnia gone? The decline of a major cladoceran in Lake Tahoe, California-Nevada. Internationale Vereinigung für theoretische und angewandte Limnologie Verhandlungen 19:835-842.

Strub, P. T., and T. M. Powell. 1986. Wind-driven surface transport in stratified closed basins: direct versus residual circulations. Journal of Geophysical Research 91:8497-8508. 